\title{
Learning opportunities in rheumatology practice: a qualitative study
}

\author{
Margit Saskia Neher, Christian Ståhl and Per Nilsen
}

Linköping University Post Print

Tweet

N.B.: When citing this work, cite the original article.

Original Publication:

Margit Saskia Neher, Christian Ståhl and Per Nilsen, Learning opportunities in rheumatology practice: a qualitative study, 2015, Journal of Workplace Learning, (27), 4, 282-297.

http://dx.doi.org/10.1108/JWL-07-2014-0054

Copyright: Emerald

http://www.emeraldinsight.com/

Postprint available at: Linköping University Electronic Press

http://urn.kb.se/resolve?urn=urn:nbn:se:liu:diva-127494 
Learning opportunities in rheumatology practice: a qualitative study

\section{Margit Neher}

Division of Social Medicine, Department of Medical and Health Sciences, Linköping

University, Linköping, Sweden

\section{Christian Ståhl}

National Centre of Work and Rebabilitation, Department of Medical and Health Sciences, Linköping University, Linköping, Sweden

\section{Per Nilsen}

Division of Social Medicine, Department of Medical and Health Sciences, Linköping University, Linköping, Sweden

Corresponding author: Margit Neher, Division of Social Medicine, Department of Medical and Health Sciences, Linköping University, SE-581 85 Linköping, Sweden. Tel: +46 10 1035110. E-mail: margit.neher@liu.se.

\section{Acknowledgments}

No conflict of interest has been declared by the authors. This research received no specific grant from any funding agency in the public, commercial, or not-for-profit sectors.

\section{About the authors}

Margit Neher has been working as a registered occupational therapist and is currently completing her $\mathrm{PhD}$ thesis in the field of implementation. 
Christian Ståhl, $\mathrm{PhD}$, is a sociologist and specialist in work disability prevention research, focusing on social security systems and coordination between stakeholders in occupational rehabilitation.

Per Nilsen is a Professor and Senior Lecturer at Linköping University, Sweden. He heads a research group investigating the implementation of evidence-based practices in health care and beyond. Nilsen takes particular interest in the challenges of achieving clinical behavior change and the use of theories, models and frameworks for improved structuring, understanding and explanation of implementation issues. 


\section{Abstract}

Background - Changes in rheumatology have led to a growing demand for practitioners to keep abreast of the scientific developments in their field. A workplace learning perspective was proposed to offer ways of exploring how knowledge, including research-based knowledge, is integrated in workplace learning processes in a rapidly evolving practice.

Purpose -To explore what opportunities for learning practitioners in rheumatology perceive of in their daily practice, using a typology of workplace learning to categorize these opportunities.

Methodology - Thirty-six practitioners from different professions in rheumatology were interviewed. Data were analyzed using conventional qualitative content analysis with a directed approach, and were categorized according to a typology of formal and informal learning.

Findings - The typology was adjusted to fit the categories resulting from the analysis. Further analysis showed that work processes with learning as a by-product in general, and relationships with other people in the workplace in particular, were perceived as important for learning in the workplace. The use of many recognized learning opportunities was lower. Barriers for learning were a perceived low leadership awareness of learning opportunities and factors relating to workload and the organization of work.

Value - The workplace learning typology that was used in the study showed good applicability to empirical health care study data, but may need further development. The study confirmed that informal workplace learning is an important part of learning in rheumatology. Further studies are needed to clarify how informal and formal learning in the rheumatology clinic may be supported in workplaces with different characteristics. 
Keywords Health care, Informal learning, Workplace learning, Evidence-based practice Paper type Research paper 


\section{Introduction}

The emergence of evidence-based medicine and its wider application as evidencebased practice has popularized the notion that research findings should be more widely utilized in health care and other settings. Evidence-based medicine has been defined as the explicit and conscientious attempt to find the best available research evidence to assist health care practitioners to make the best decisions for their patients (Sackett et al., 1996). Indeed, evidence-based approaches permeate the health fields, including nursing, public health, physiotherapy and mental health, as well as more distant fields of social work, probation, education and human resource management (Trinder and Reynolds, 2000). Health care practitioners know they are expected to ensure that they adhere to the latest evidence about best practice, yet they do not always make the best use of the new sources of evidence such as clinical guidelines and systematic reviews of clinical trials (Dougados et al., 2004, Nutley et al., 2007).

In similarity with professionals in many other health care contexts, there is an increasing need for rheumatology practitioners to go beyond formal training to learn a range of new skills as practice is becoming more complex (Woolf, 2007). Rheumatology has undergone dramatic changes in recent years with the development of new treatment options. New research findings in such areas as genomics and genetics, proteomics, biologic therapies and diagnostic and investigational radiology have emerged (Klareskog et al., 2005). These changes have led to a growing demand for rheumatology practitioners to keep abreast of the developments in their field and to develop a high level of research literacy (Bartels, 2009).

It is generally accepted that a great deal of learning occurs through informal workplace learning, i.e. learning through experience and interactions with colleagues, without 
a curriculum and independently from instructor-led programs (Ellström and Illeris, 2004, Mc Kee and Eraut, 2012). The challenges of work itself, the organization of work and the social interactions at work tend to be important sources of informal workplace learning in many practice contexts (Antonacopoulou et al., 2006). Learning in rheumatology practice has not been the focus of much research. In fact, we have not been able to find any studies which have investigated learning opportunities in rheumatology. Addressing an important knowledge gap, this study is aimed at exploring what opportunities for learning practitioners in rheumatology perceive of in their daily practice, using a typology of workplace learning developed by Eraut (2007).

\section{Theoretical framework}

We applied a learning typology developed by Eraut (2007) that has been shown to be useful in the Swedish context (Wallman, 2011). The typology characterizes two main learning processes at work: working processes with learning as a by-product and recognized learning processes. The typology also describes learning activities that are embedded in both of these processes (Eraut, 2007).

Formal workplace learning tends to consist of an organized learning event, with a designated teacher or trainer, following a curriculum with explicit learning objectives and often including assessment and the award of a qualification or credit upon completion (Eraut, 2007). Informal learning has been perceived as distinct from formal learning (Marsick and Watkins, 1990) and is sometimes defined as all learning not identified as formal. Eraut conceptualizes informal learning as a continuum including implicit learning, on-the-spot reactive learning and deliberative learning. Implicit learning is sometimes referred to as socialization or tacit learning (Merriam et al., 2007). Reactive learning is explicit but takes place almost simultaneously when responding to recent, current or imminent situations 
without setting aside time for learning. Eraut (2000) proposes that the significance of implicit and reactive learning may be greater than that of deliberative learning, and that the role of tacit knowledge is particularly important. Tacit knowledge includes the understanding of people and situations, routinized actions and the tacit rules that underpin intuitive decisionmaking. While learning can be incidental, and an accidental by-product of doing something else, it is possible to become aware of having learned something afterwards (Marsick and Watkins, 1990). Some part of this tacit knowledge may be codified through reflection and metacognition (Schön, 1983, Mc Kee and Eraut, 2012). Leadership, structure, climate, culture, systems and practices, incentives and rewards have been identified as important influencing factors (Marsick, 2009b, Eraut, 2007, Ellström and Illeris, 2004).

\section{Methods and materials}

The study was based on individual and small-group interviews, which were analyzed using directed qualitative content analysis (Hsieh and Shannon, 2005).

\section{Study participants}

Health care in Sweden is publicly funded, with equal access for the entire population and fees regulated by law. The provision of health care services is the responsibility of the 21 county councils and carried out by both private and public actors. Patients requiring specialized care and medication are cared for mostly in hospital clinics, and approximately 900 practitioners work in specialized rheumatology.

Participants were recruited through managers and other key persons in different clinical settings in Sweden via an email describing the study. The request was sent to all known rheumatology clinics in Sweden, including private practices. To be eligible for the study, participants had to work in clinical practice with patients who had rheumatic disorders. 
This study involved 36 practitioners in 10 rheumatology work units from 9 county councils in Sweden. Interviews were conducted from May 2012 to February 2013. Five of the participants in the study were rheumatology specialists, 12 were registered nurses, 10 were physiotherapists, 8 were occupational therapists, and 1 was a social worker. The participants varied in age from 34 to 67 years (average 49 years). Ten of the participants were relatively inexperienced; they had worked from 6 months to 3 years in the field of rheumatology. The other participants had more than 3 years and up to 37 years of work experience in the specialty; 34 participants were women and 2 were men.

Of the 10 work units studied, 6 were small (2-19 practitioners working in rheumatology), 2 were medium sized (20-44 practitioners) and 2 were large (>45 practitioners). The units were geographically widespread and located in rural and urban areas. Participants in the study were working full- or part-time in rheumatology. Some worked in a shared specialty clinic, often in conjunction with (subspecialties of) internal medicine. None of the participants worked in a private practice.

\section{Data collection}

The interview guide was developed by the authors. Before the interviews, the questions were pilot tested. The pilot-interviews showed that questions were generic enough to be used between different professions, that the wording was clear, and that the interview did not exceed one hour (which was deemed to be most likely the maximum in participants' work schedule).

Each interview started with an open question asking the informants to describe their responsibilities in their daily work and their own professional history. The interview then focused on several broad areas of interest: how new knowledge is acquired and shared and 
what was perceived to influence learning processes. Questions were open ended to allow participants to choose which aspects they wished to focus on, and it was left to participants to define the concept of knowledge and learning. Interviews continued until responses did not yield substantial additional variations in the types of opportunities that were mentioned.

The interviews were conducted by the first author during regular working hours to facilitate participation. Most interviews were individual, but at their own request, four groupinterviews were conducted with two-three professionals from the same profession (a total of 10 informants). Each interview lasted between 45 and 60 minutes.

\section{Data analysis}

Interviews were transcribed after completion and assigned identification codes. A computer package (NVivo 10) assisted the analysis by sorting the transcribed text from interviews into a developing content system. Analysis started in parallel with the data collection, and the initial results informed subsequent data collection.

The data were analysed as a whole using a form of directed qualitative content analysis. Qualitative content analysis is a technique for analysis of texts grounded in empirical data with an explorative and descriptive character (Krippendorff, 2004). In the directed approach, categories from a pre-existing typology or framework are used to help focus the research question (Hsieh and Shannon, 2005). We chose to use an explorative approach in the beginning of the analysis, and then to map the emergent categories into the theoretical framework in the second stage. In this way, our analysis was assisted by the existing framework but not limited by it.

To enhance the trustworthiness in this study even more, the authors analyzed parts of the texts separately in the explorative first phase of the analysis process, each using their own 
professional knowledge from their different backgrounds. Initial analyses were presented by the first author, who had prior experience in clinical rheumatology, whereupon extensive and iterative discussions were undertaken to arrive at codes and categories that were satisfactory to all the authors. In the second phase, the same systematic process was followed while mapping these categories into the typology.

The authors started by reading the transcripts to obtain an understanding of the whole. As the goal of the study was to identify and categorize all instances of learning opportunities in clinical rheumatology, all the text that seemed to represent these opportunities was highlighted. The researchers approached the text several times. During this process, codes that reflected more than one key statement or thought were developed; the codes were then aggregated into clusters based on similarity of content and their relation to each other. After re-examination, the initial clusters were merged into categories, which were given labels that provided an overall description of their content (Hsieh and Shannon, 2005). To enhance the internal validity, the categories were cross-examined to ascertain that they were defined in such a way that they were as internally homogeneous as possible and as externally heterogeneous as possible (Krippendorff, 2004).

In the second phase, all the categories were classified using the aforementioned typology of formal and informal learning developed by Eraut (2007). Any inductively constructed category that could not be classified in the typology was given a new code.

Internal validity was strengthened by discussions about this mapping process, which continued until no inconsistencies existed and a shared understanding was reached (Patton, 2002). Representative quotations were identified to illustrate the findings. Quotations were then translated from Swedish to English.

\section{Ethical considerations}


The informants were assured of the confidentiality of the data, that participation in the study was voluntary and that they could withdraw at any time during the interview. The regional ethics board approved the study.

\section{Results}

Our study shows that the adjusted typology of formal and informal learning was useful to categorize our findings. The study also showed that non-formal learning opportunities were perceived as important and that relationships in the workplace with peers, patients and others were central to learning in the workplace, while opportunities in recognized learning processes were more limited. While the study focused on the participants' perceptions of learning opportunities, perceptions linked to the support for learning in the organization were also expressed.

The learning opportunities in rheumatology practice are presented in Table 1. The typology was adjusted to fit the categories found in our study.

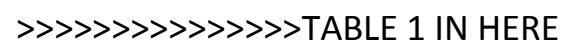

\section{Adjustment of the typology}

Some adjustments were made to the typology for a better fit with the data in our study. Problem solving, defined as "acquiring new knowledge before one can start, searching for relevant information and informants" was found to overlap with other categories, such as participation in group processes, consulting with others and independent study. Some categories were also collapsed. Trying things out and consolidating, extending and refining skills were combined, as both categories implied an intentional professional skill development. 
The first four separate categories listed as recognized learning processes in the original typology, "being supervised, being coached, being mentored and shadowing" were not mentioned by our participants.

None of the study participants mentioned working for a qualification (outside of personal initiatives to formally update their professional knowledge), because there is no compulsory qualification system beyond professional accreditation in Sweden.

\section{Work processes with learning as a by-product}

Participation in group processes included profession-specific meetings and exchanges with colleagues from other professions. All participants perceived professional meetings within their peers to be one of the most rewarding opportunities for learning. These meetings were for the most part informal and focused on profession-specific areas of interest. A nurse in a medium-sized clinic (9) observed that discussion on extended responsibilities for nurses was a reason for meetings: "We really needed to discuss how to apply what we had heard, we were so enthusiastic!”. A physiotherapist (25) said: "Before all the cut-backs, we worked together as a group to find research that showed how to achieve a higher pulse in patients with arthritis, as they have a higher risk for heart-related disease”.

Organized exchanges with colleagues from other professions focused mostly on patients and their needs. In that respect, participating in rounds and patient conferences were seen as important learning activities. More spontaneous inter-professional exchanges were perceived to depend on either physical proximity and/or on close personal knowledge of the other practitioners. A physician in a large clinic (2) observed: "We have continuous communication. We're so close to each other in the clinic. We can stop each other in the corridor, or we are stopped by someone". A nurse in another unit (16) noted: "The social 
worker has her offices in our unit, but the physiotherapists and occupational therapists do not. They don't have their breaks together with us, so we don't...we don't see them as naturally'. An occupational therapist in another work unit (24) perceived that not knowing much about the responsibilities of other professions affected care: "The physiotherapist and I are called 'the team'. We get referrals to our practice from doctors who come in for short stints. They don't know what we can do. Sometimes they think we can do too much, and sometimes they don't know we exist".

Consultations included opportunities for both professional and inter-professional learning. Participants most often sought professional advice in their own group. When asked what to do when problems were encountered in daily practice, a physician in a large clinic (15) answered: “On Thursdays and Fridays, we have peer meetings in our unit with our supervisor, that's when I ask questions like that". A physiotherapist in a large clinic (1) expressed that: "Our ambition is to set aside the time to exchange experiences in our professional group. It is in those situations that I personally feel I can ask about something I can't solve". Inter-professional consultations were often described as taking place during coffee breaks and other informal situations, but they nevertheless gave informants important feedback. "We nurses usually eat lunch with the physicians and nursing assistants, all together, and that's when we discuss things", said an experienced nurse in a large work unit (16). A new nurse in a rural area (27) had to cope mostly on her own: "I get instructions from the specialist through our electronic communication system. If there is a problem, he asks me to book her for a doctor's consultation soon. 'Soon' can be a month. Then I usually ask one of the other doctors in our hospital”.

Learning opportunities by way of working alongside others, trying things out and consolidating, extending and refining skills were most often applicable to those with less experience. Novices expressed their appreciation of their colleagues. A new occupational 
therapist (8) said: "Sometimes I feel uncertain, and tell my patient that we have to book a new meeting so that I can consult with my more experienced colleague, or I ask my colleague to come and have a look at the patient's hand. It's so much better than trying to read a textbook". More experienced workers often did not work alongside others, but expressed a need for reflection and more time to process their experiences, especially when undertaking challenging tasks and roles.

Working with patients was also mentioned by many as a significant learning activity, leading to a deeper personal understanding of the perceptions and consequences of disease and clarifying what treatments worked and what did not, but also as a way of building a relationship with the patient over time. A novice social worker (19) said: "Patients are experts at their own bodies, and if you listen you find out a lot about their situation and their disease and so on. I find that there are no universal solutions". A physiotherapist said: "I evaluate all the time how the patient responds to my treatment. I learn so much from that”. Individual patients were sometimes a source of knowledge for practitioners as well. A novice nurse (11) observed: "There are some patients who are very well informed, you know".

Unassigned teaching was perceived to provide opportunities for learning by several experienced participants. A physician (22) with a formal teaching role for other specialties in the hospital supported a part-time nurse starting her career in a rural area: "I perceive that it's my responsibility. I work at least half an hour every day with her, to teach her the things she needs to know". An occupational therapist supplied her less experienced colleagues with new information. Her colleague (8) said: "B, who is really good at rheumatology, knows that I need information, so nearly every week she leaves me interesting papers and reports and such to read!" 
Research activities were often perceived as learning opportunities, as well as presenting network opportunities. An experienced physiotherapist (1) explained: "Because of the research project that we were involved in, my colleagues and I came into contact with other physiotherapists and learned a lot together. Now we can ring and talk to them if we need to, because we know them a little, having met face to face". A nurse who assisted in collecting data in a research project (12) said: "I work part-time with the national quality register and we are learning to use the register as a decision support system just like the physicians do". Another nurse (16) said: "Often we use a study protocol about a medication we are planning to start using in the clinic, so that's practical".

\section{Recognized learning processes}

Direct supervision by line managers, designated mentors and coaching were not or scarcely mentioned by the participants. A nurse in a small clinic (3) said: "My manager doesn't know what I can do, and I don't think he cares". Instead, managers were perceived to be connected with the implementation of organisational change. A physician in a rural area (26) expressed: 'Since the recent re-organization, I don't have a team to collaborate with anymore. The health professionals in primary care, where I send my patients now often have not kept up with developments in rheumatology." A physiotherapist (25), also in a rural clinic, echoed this: "I've been working with rheumatology since the 1980 s, and have seen the rise and fall of the county council. It's frustrating to be working in this new cutback situation".

Visiting other sites was perceived as a valuable way to explore alternative work routines and organizational matters. However, visits were not prompted primarily by individual learning needs. In several cases, the study visits were undertaken as part of moving towards clinical change, e.g. nurse-led clinics or new types of interventions. But visiting other 
clinics was limited because of the costs involved in some cases. A physiotherapist (4) in a small remote clinic said: "It's natural, really. It's a matter of geography".

In-house lectures, including visits from pharmaceutical companies were valued by all study participants, but not all participants attended them. A new physiotherapist in a small clinic (32) said: "Sometimes we get to go to these pharmacological visits. But mostly we have to fight for it. The medical staff don't understand that we [rehabilitation staff, author's note] need to understand the medication too, because we get a lot of questions from patients. And we need to take inflammatory activity into consideration in our treatment".

Regional and national rheumatology conferences and short courses were mentioned by several practitioners as networking opportunities. Attending regional conferences was planned on a once-a-year basis, but many did not participate regularly or very often. A physiotherapist in a small clinic (33) said: “I haven't been to a course or conference for at least three years, there's no money". Many of the allied health professionals in the study perceived that specialized short courses were not available to them at the postgraduate level. Another physiotherapist said that her clinic had a general education restriction for all staff during the preceding year: "I don't know if it has let up yet. But to be honest I'm not sure there are all that many courses out there".

Opportunities for continuing professional education were mentioned by an experienced rheumatologist (22) as a recruitment strategy for rural areas in northern Sweden: "When I applied for the job, they offered me everything I wanted in the way of continuing professional education, even though I only work part-time in the clinic". Other physicians also said that they could choose any conferences or courses, but that the work pressure in the clinic often limited their participation. One physician in a small understaffed clinic (4) said: "My 
boss would probably let me participate in any meetings and conferences I want, but I feel that knowing how things will be in the clinic when I get back is a barrier for me".

Time for independent study was scarce in most units. A physician (2) had a half-day set aside for planned learning, but that time was often used to catch up on administrative chores instead: "I always have a bad conscience about that. There are so many practical matters that need to be done, and then I prioritize them. You think you will have some time to study, but...it doesn't happen". Some informants did their best to prepare for upcoming patient encounters by self-study in their spare time. An experienced occupational therapist in a small clinic (7) said: "I had a patient with an unusual diagnosis a while ago, and I thought I would update my knowledge. But it's absolutely impossible to sit and read a book here, in the clinic, so you take it home, it's the only way".

Assigned teaching was valued by some participants. Having trainees involved formal training and stimulated self-directed learning. Some participants in the medical profession had a more formal role in educating their colleagues or had formal consulting responsibilities in the larger hospital context. An experienced physician (26), who worked part-time in rheumatology, had a supervisor to discuss more complicated cases with: "It's a matter of feeling comfortable with your responsibilities. It's a legal thing, too".

Research projects gave some participants the opportunity to learn about the research subject and to consider applying the results from research to practice. A nurse (12) with a $\mathrm{PhD}$ in nursing explained: "I have a tough time convincing other nurses about the results from my own research, because it's rather inconclusive. But I help to spread other research into practice".

\section{Discussion}


The learning opportunities that were found in this study were largely in accord with those proposed in the typology (Eraut, 2007). The adjustments were a collapse of categories and a proposed addition of categories. Differences between the original typology and ours may depend on the manner of data collection. In interviewing (our method), the narratives of individuals are personal in nature. This contrasts with Eraut's method of observation, which may be more influenced by the observer. Also, differences in the overall professional maturity of the study participant group may be important, as many participants in our study had a long experience in the field, whereas Eraut's original typology was based on employees in early and middle careers.

Differentiating between the two processes was not always easy. For example, in-house meetings and visits from pharmacological companies had as their principal object learning rather than working and were categorized as learning opportunities within the recognized learning processes, although they neither had a specified learning outcome. In participation in group processes the focus was on solving work-related problems and sharing patient-related information, and these opportunities were categorized as being part of non-formal learning processes. Considering that these group processes may very well have a type of knowledge exchange agenda, it is clear that the distinction was not clear-cut.

We identified two new categories that may possibly enhance the original typology: teaching activities and learning through involvement in research. Choosing to engage in these roles may reflect individual choice. The agency of the individual (beliefs, values, histories and prior socialization of the individual) has been acknowledged as playing an important role in the enactment of the work role (Billett, 2008). The categories may also reflect characteristics of the work environment. These characteristics were possibly practical aspects (e.g. having access to research projects) but maybe also intentional strategies at the organizational level (e.g. choosing to involve workers in a research project or organize knowledge exchange). The 
proposed new categories may serve as a useful addition to the original typology when studying learning opportunities for more experienced workers, but further studies are needed to confirm these findings.

This study found that working processes with learning as a by-product was a major source of learning in rheumatology practice. These findings are in accord with previous research, as the importance of informal learning for acquiring and developing the skills and competencies required at work has been increasingly recognized (Elkjaer and Wahlgren, 2006, p 21). At the same time, research also supports combining informal learning processes with more formal learning, as many authors propose that the processes interact and can best considered to be complementary to each other (Bell and Dale, 1999, Svensson et al.,2004, Marsick, 2009a) That our findings so clearly reflected the importance of working processes with learning as a by-product is interesting, because other research has shown that studying informal learning processes has inherent difficulties: informal learning is often not recognized by the learners themselves because it is a normal, taken-for-granted part of work (Marsick, 2009a).

We found that relationships with professional peers, patients and practitioners from other professions were perceived as important learning opportunities and enablers for learning at work. Peer discussions were perceived by most participants as an opportunity for learning and for feedback on professional performance. Discussions concerned patient-related problems, treatment options and more general professional issues. Marsick (2009) sees social support, including getting and using ideas from others, coaching, learning from mistakes, giving and receiving feedback as one of the most important enablers for informal workplace learning and of key importance for building informal learning communities (Marsick, 2009b). Normative feedback on strengths and weaknesses and attention to the emotional side of working life are also found to be important for learning (Eraut, 2007). 
Perceptions linked to the support for learning in the organization showed that while relationships in the workplace with peers, patients and others were valued as enablers for learning, many barriers were also identified. These included a low awareness of the importance of learning in the workplace at the organizational level, with a limited formal support of inter-professional knowledge exchange and structures for shared reflection and knowledge-sharing, including support for novices. Staff shortages and the resulting high work load restricted independent study and participation in courses and conferences.

Explanations for the barriers in the study were often seen as resting with economic restrictions and the organization of work. In our study, first-line managers were not perceived as supervisors other than in a very general sense. This is not in accord with most literature, which regards the influence of managers on both individual workplace learning and the workplace learning culture as being of key importance. At the individual level, research shows that career development and planning help promote workplace learning (Cofer, 2000), ant that managers should use technology and person-based knowledge management tools to link individually generated informal learning and accessibility of knowledge (Eraut, 2012, p 28, Matthews, 2013). The constrained learning culture in most workplaces in this study entailed limited opportunities for knowledge-sharing. Health professionals in some work units perceived that teamwork had diminished. In the last ten years or so, many hospitals had differentiated the organizational affiliation for professional groups. In some instances the team members' shared working history had disappeared together with the turn-over in employees. There also was less physical proximity, which may have fractured previously more cohesive teams. As inter-professional collaboration, by virtue of its multiple competence bases, often is perceived to offer solutions in more complicated situations this is problem for those patients who have co-morbidities or psychosocial issues that aggravate their rheumatic disease (Thylefors et al., 2005, Reeves, 2010). It also affects workplace learning: to work 
together, practitioners from separate professional backgrounds and knowledge areas need to integrate their knowledge to learn "with, from and about each other" (Center for the Advancement of Inter-professional Education, 2002).

None of the novices in the study mentioned supervision, coaching, mentoring or shadowing as formally instituted. Instead, novices were reliant on their more experienced colleagues who introduced them to practice as well as they could within the limitations of their own clinical workload. As most learning theories stress the importance of feedback and support, especially in the initial phases of a professional career, these omissions may be viewed with some concern. The need for a strong mentor or supportive colleague to help one learn a job on the basis of informal learning is underscored by many sources (Conlon, 2004, Eraut, 2007, Marsick, 2009b). The role of mentor or coach may be beneficial for more experienced workers as well. As well as aiding the novice by supplying valuable support and feedback, these strategies may supply the experienced worker with the opportunity to codify their tacit knowledge and stimulate their own learning through shared reflection (Garrick, 1998, Mc Kee and Eraut, 2012).

As time for independent study and participation in conferences and courses was perceived as limited, the implementation of evidence-based practice may have been affected. Outside of individual barriers, lack of support from peers, managers and other health professionals, lack of resources and resistance to change, insufficient time within work commitments has been shown to restrict the use of research-based knowledge (McSherry and Pearce, 2010, p 71-72). As Eraut (2000) noted, deliberate cognition leads to learning in situations of uncertainty, but being able to make time for this activityis of the essence. To stop and consider alternatives, to discuss issues with colleagues and to check the available scientific evidence is time-consuming. Because experiential tacit knowledge is always "with us", this will usually prevail in situations of time pressure (Eraut, 2000). We do not know 
which learning opportunities in particular were used to update research-based knowledge, and opportunities in both processes could theoretically provide this knowledge. The differences between individuals in agency, ability and motivation for accessing this type of knowledge will have to be recognized and respected, but promoting learning in the workplace in all its forms, using channels for the sharing of all kinds of knowledge could be a powerful way to support evidence-based practice in rheumatology.

\section{Limitations and strengths}

This study has some limitations that must be considered when interpreting the results. A limitation of the directed approach is that researchers may be more likely to find evidence that is supportive rather than non-supportive of a theory (Hsieh and Shannon, 2005). We chose a two-step data analysis strategy, which was aimed at capturing all possible occurrences of the phenomenon (opportunities for learning in the workplace), before we used the typology as a classification system. This process can be said to increase trustworthiness (Hsieh and Shannon, 2005). Nevertheless, our results should be interpreted with some caution. Further studies may add or remove categories.

With respect to the application of Eraut's typology, we recognize that there are elements of informal learning in formal learning situations and vice versa (Malcolm et al., 2003). Also, as some forms of tacit learning are difficult to study, we have only covered part of the informal learning that occurs. However, the dichotomy that was used in the study provided a structure for organizing the findings and facilitated the exploration of a complex reality.

For pragmatic reasons, the study is based on one-to-one interviews as well as interviews in small groups. Mixing data types may limit the rigour of the study method, as 
informants' expressions may be influenced by group dynamics (Lambert and Loiselle, 2008). Also, the scope of our enquiry did not allow for an exploration of differences between professional groups, but this may be of interest to study further, as differences may be expected.

Issues of interviewer bias and social desirability bias are inherent risks in qualitative methodology. An advantage in this study was that the interviewer was cognizant of the clinical milieu, while not knowing the participants. The exploratory nature of this qualitative enquiry gave a range of opportunities that relate to a small group of practices and participants, and it is the readers' task to determine if the results are applicable to a wider context.

\section{Conclusions}

In conclusion, we found that working processes with learning as a by-product were a major source of learning in rheumatology practice, that there were relatively few opportunities for recognized learning processes, and that the organizational awareness of learning opportunities in the workplace was perceived to be low. In the clinical context, locally adapted strategies at organizational and individual levels are needed to maximize opportunities for informal learning, taking the importance of personal relationships into account. The findings also suggest a need for increased continuing professional education in the specialty. Both first-line managers and their organizational leaders at the county council level have a responsibility to facilitate health professionals' participation in continuing education; the responsibility for supplying educational interventions lies with the education system. This study hopes to have contributed to raising the awareness of clinical leaders of the range of ways in which people can learn in the workplace, and to recognize the factors which hinder or enhance individual and group learning in rheumatology. Future research should focus on exploring how informal and formal opportunities may best enhance learning in 
workplaces with different local needs. Another interesting aspect to study further is how these opportunities differ for different professional groups, and if the proposed additions to the typology represent learning opportunities that can be found in other work environments.

ANTONACOPOULOU, E. P., JARVIS, P., ANDERSEN, V., ELKJÆR, B. \& HØYRUP, S. 2006. Learning, working and living : mapping the terrain of working life learning, Houndmills, Basingstoke, Hampshire ;, Palgrave Macmillan. 
BARTELS, E. M. 2009. How to keep up with medical literature. Best Practice \& Research Clinical Rheumatology, 23, 281-290.

BELL, J. \& DALE, M. (1999), “Informal learning in the workplace, Department for Education and Employment, Research Report No 134", available at http://webarchive.nationalarchives.gov.uk/20130401151655/https://www.education.go v.uk/publications/standard/publicationDetail/Page1/RB134 (accessed 4 April 2014).

BILLETT, S. 2008. Learning throughout working life: a relational interdependence between personal and social agency British Journal of Educational Studies, 56, 39-58.

Centre for the Advancement of Interprofessional Education (2002), "Defining interprofessional education“, available at http://www.caipe.org.uk/about-us/definingipe/ (accessed 12 May 2014).

COFER, D. A. 2000. Informal learning in the workplace: A Brief Review of Practice and Application. U.S. Department of Education, Educational Resources Information Center, 1-7.

CONLON, T. J. 2004. A review of informal learning literature, theory and implications for practice in developing global professional competence. Journal of European Industrial Training, 28, 283-295.

DOUGADOS, M., BETTERIDGE, N., BURMESTER, G. R., EULLER-ZIEGLER, L., GUILLEMIN, F., HIRVONEN, J., LLOYD, J., OZEN, S., DA SILVA, J. A. P., EMERY, P., KALDEN, J. R., KVIEN, T., MATUCCI-CERINIC, M. \& SMOLEN, J. 2004. EULAR standardised operating procedures for the elaboration, evaluation, dissemination, and implementation of recommendations endorsed by the EULAR standing committees. Annals of the Rheumatic Diseases, 63, 1172-1176. 
ELLSTRÖM, P.-E. \& ILLERIS, K. 2004. Workplace learning - Scandinavian perspectives [Elektronisk resurs] Guest editors Per-Erik Ellstrom and Knud Illeris, Bradford, England : Emerald Group Publishing, c2004.

ELKJAER, B. and WAHLGREN, B. (2006), “Organizational learning and workplace learning-similarities and differences", in Antonacopoulou, E.P., Jarvis, P., Andersen, V., Elkjær, B. and Høyrup, S. (Eds.), Learning, Working and Living : Mapping the Terrain of Working Life Learning, Palgrave Macmillan, Basingstoke, UK, p. 21

ERAUT, M. 2000. Non-formal learning and tacit knowledge in professional work. British Journal of Educational Psychology, 70, 113-136.

ERAUT, M. 2007. Learning from other people in the workplace. Oxford Review of Education, 33, 403-422.

ERAUT, M. 2012. Developing a Broader Approach to Professional Learning, in MC KEE, A. \& ERAUT, M. 2012. Learning trajectories, innovation and identity for professional development [Elektronisk resurs] / Anne Mc Kee, Michael Eraut, editors, Dordrecht ; New York : Springer, c2012.

GARRICK, J. 1998. Informal learning in the workplace : unmasking human resource development, London, Routledge.

HSIEH, H. F. \& SHANNON, S. E. 2005. Three approaches to qualitative content analysis. Qualitative Health Research, 15, 1277-1288.

KLARESKOG, L., SAXNE, T. \& ENMAN, Y. 2005. Reumatologi, Lund, Studentlitteratur. KRIPPENDORFF, K. 2004. Content analysis : an introduction to its methodology, Thousand Oaks, Calif., Sage.

LAMBERT, S. D. \& LOISELLE, C. G. 2008. Combining individual interviews and focus groups to enhance data richness. Journal of Advanced Nursing, 62, 228-237. 
MALCOLM, J., HODKINSON, K. \& HELEN, C. 2003. The interrelationships between informal and formal learning. Journal of Workplace Learning, 15, 313-318.

MARSICK, V. J. 2009a. Toward a unifying framework to support informal learning theory, research and practice. Journal of Workplace Learning, 21, 265-275.

MARSICK, V. J. 2009b. Towards a Unifying Framework to Support Informal Learning Theory, Research and Practice [Elektronisk resurs], Bradford, Emerald Group Publishing Limited.

MARSICK, V. J. \& WATKINS, K. E. 1990. Informal and incidental learning in the workplace, London, Routledge.

MATTHEWS, P. 2013. Informal Learning at work. How to boost performance in tough times, Milton Keynes, UK, Three Faces Publishing.

MC KEE, A. \& ERAUT, M. 2012. Learning trajectories, innovation and identity for professional development [Elektronisk resurs] / Anne Mc Kee, Michael Eraut, editors, Dordrecht ; New York : Springer, c2012.

MCSHERRY, R. \& PEARCE, P. 2010. Clinical Governance, 3rd Edition, John Wiley \& Sons.

MERRIAM, S. B., CAFFARELLA, R. S. \& BAUMGARTNER, L. M. 2007. Learning in adulthood : a comprehensive guide, San Francisco, Calif., Jossey-Bass, A Wiley Imprint.

NUTLEY, S. M., WALTER, I. \& DAVIES, H. T. O. 2007. Using evidence : how research can inform public services / Sandra M. Nutley, Isabel Walter and Huw T.O. Davies, Bristol : Policy Press, 2007.

PATTON, M. Q. 2002. Qualitative research \& evaluation methods / Michael Quinn Patton, London : SAGE, 3. ed. 
REEVES, S. 2010. Interprofessional teamwork for health and social care, Chichester, West Sussex, Blackwell.

SACKETT, D. I., ROSENBERG, W. M., GRAY, J.A,, HAYNES, R. B. \& \& RICHARDSON, W. S. 1996. Evidence based medicine: what it is and what it isn't. British Medical Journal, Jan 13, 71-2.

SCHÖN, D. A. 1983. The reflective practitioner: How professionals think in action, New York, N.Y., Basic Books.

THYLEFORS, I., PERSSON, O. \& HELLSTRÖM, D. 2005. Team types, perceived efficiency and team climate in Swedish cross-professional teamwork. Journal of Interprofessional Care, 19, 102-114.

TRINDER, L. \& REYNOLDS, S. 2000. Evidence-based practice : a critical appraisal, Oxford, Blackwell Science.

WALLMAN, A., GUSTAVSSON, MARIA, KETTIS LINDBLAD, ÅSA AND RING, LENA 2011. An Exploration of how Students learn in a Pharmacy Internship. 11, 177-182.

WOOLF, A. D. 2007. Healthcare services for those with musculoskeletal conditions: a rheumatology service. Recommendations of the European Union of Medical Specialists Section of Rheumatology/European Board of Rheumatology 2006. Annals of the Rheumatic Diseases, 66, 293-301. 


\section{Learning opportunities Explanation of learning opportunity (Eraut) by type of learning process (Eraut)}

Opportunities for learning in clinical rheumatology practice found in this study

\begin{tabular}{|c|c|c|}
\hline \multicolumn{3}{|c|}{ Recognized learning processes } \\
\hline Visits to other sites & $\begin{array}{l}\text { Formal extensions to the observation opportunities } \\
\text { available through learners' normal work }\end{array}$ & $\begin{array}{l}\text { Study visit to other rheumatology } \\
\text { clinics }\end{array}$ \\
\hline Conferences & Structured meetings with an agenda* & $\begin{array}{l}\text { In-house lectures for all staff; } \\
\text { pharmacological company visits; } \\
\text { regional, national and international } \\
\text { rheumatology conferences }\end{array}$ \\
\hline Short courses & $\begin{array}{l}\text { Structured meetings with a curriculum and in some } \\
\text { cases a knowledge assessment of the participant* }\end{array}$ & $\begin{array}{l}\text { Specialty course at university; } \\
\text { professional course; course through } \\
\text { pharmaceutical company; formal in- } \\
\text { house exchange with other specialties }\end{array}$ \\
\hline Independent study & $\begin{array}{l}\text { Training supported by knowledge resources and/or } \\
\text { agreed plans, such as lists of competences, learning } \\
\text { projects or personal development plans }\end{array}$ & $\begin{array}{l}\text { Searching and reading research } \\
\text { articles, books, popular journals, } \\
\text { internet resources }\end{array}$ \\
\hline $\begin{array}{l}\text { Proposed new } \\
\text { categories/learning } \\
\text { opportunities by the } \\
\text { authors: }\end{array}$ & $\begin{array}{l}\text { Explanation of proposed new categories/learning } \\
\text { opportunities by the authors }\end{array}$ & In rheumatology practice: \\
\hline Assigned teaching role & $\begin{array}{l}\text { Formally recognized professional or inter-professional } \\
\text { teaching responsibilities towards students and/or peers } \\
\text { in or outside the clinical specialty* }\end{array}$ & $\begin{array}{l}\text { Supervising students and receiving } \\
\text { concomitant training; coordinating } \\
\text { continued professional education in the } \\
\text { clinic; formal consulting role }\end{array}$ \\
\hline $\begin{array}{l}\text { Research activities } \\
\text { (project manager) }\end{array}$ & $\begin{array}{l}\text { (Co-)managing a research project, responsible for } \\
\text { producing end results of study* }\end{array}$ & $\begin{array}{l}\text { Using research results to inform } \\
\text { practice }\end{array}$ \\
\hline
\end{tabular}

\section{Working processes with learning as a by-product}

\begin{tabular}{lll}
\hline $\begin{array}{l}\text { Participation in group } \\
\text { processes }\end{array}$ & $\begin{array}{l}\text { Team working towards a common outcome, and groups } \\
\text { set up for a special purpose such as discussing a client, } \\
\text { problem solving, reviewing some practices, planning } \\
\text { ahead or responding to external changes }\end{array}$ & Informal professional meetings \\
& $\begin{array}{l}\text { Consultations within or outside the working group or } \\
\text { even outside the organization, used to coordinate } \\
\text { activities or to get advice }\end{array}$ & $\begin{array}{l}\text { Personal consulting with colleagues } \\
\text { with specialized knowledge or more } \\
\text { experience in the clinic or with } \\
\text { colleagues in other specialty units }\end{array}$ \\
\hline Consultation & & $\begin{array}{l}\text { Learning from peers in the course of } \\
\text { clinical practice }\end{array}$ \\
\hline $\begin{array}{l}\text { Working alongside } \\
\text { others }\end{array}$ & $\begin{array}{l}\text { Working alongside others allows people to observe and } \\
\text { listen to others at work }\end{array}$ &
\end{tabular}




\begin{tabular}{|c|c|c|}
\hline $\begin{array}{l}\text { Tackling challenging } \\
\text { tasks and roles }\end{array}$ & $\begin{array}{l}\text { Tackling challenging tasks and roles requires on-the-job } \\
\text { learning and, if well supported and successful, leads to } \\
\text { increased motivation and confidence }\end{array}$ & $\begin{array}{l}\text { Reflection on one's own clinical } \\
\text { experience }\end{array}$ \\
\hline $\begin{array}{l}\text { Trying things out; } \\
\text { consolidating, } \\
\text { extending and refining } \\
\text { skills }\end{array}$ & $\begin{array}{l}\text { Trying things out is distinguished from less purposeful } \\
\text { behaviour by the intention to learn from the experience }\end{array}$ & Practicing professional skills \\
\hline Working with clients & $\begin{array}{l}\text { Entails learning (1) about the client, (2) from any novel } \\
\text { aspects of each client's problem or request and ( } 3 \text { ) from } \\
\text { any new ideas that arise from the encounter. There can } \\
\text { also be a strong emotional dimension }\end{array}$ & Learning from patients \\
\hline $\begin{array}{l}\text { Proposed new } \\
\text { categories/learning } \\
\text { opportunities by the } \\
\text { authors: }\end{array}$ & $\begin{array}{l}\text { Explanation of proposed new categories/learning } \\
\text { opportunities by the authors: }\end{array}$ & In rheumatology practice \\
\hline $\begin{array}{l}\text { Unassigned teaching } \\
\text { role }\end{array}$ & $\begin{array}{l}\text { Purposeful sharing of knowledge and skills with peers } \\
\text { and patients to enhance quality of care, without mandate } \\
\text { or curriculum* }\end{array}$ & $\begin{array}{l}\text { Preparing an informal session with the } \\
\text { professional group; sharing research } \\
\text { literature with peers; patient education; } \\
\text { unofficial consulting role }\end{array}$ \\
\hline $\begin{array}{l}\text { Research activities } \\
\text { (assisting) }\end{array}$ & $\begin{array}{l}\text { Being involved in a research project, without being } \\
\text { responsible for producing end results of study* }\end{array}$ & $\begin{array}{l}\text { Being informed by researchers about a } \\
\text { research project, before and in the } \\
\text { course of collection and registration of } \\
\text { study data }\end{array}$ \\
\hline
\end{tabular}

Table 1. Opportunities for learning in clinical rheumatology practice, based on a typology of early career learning (Eraut, 2007). ${ }^{*}=$ Explanation by authors. 